or areas of the limb, contrast enhanced magnetic resonance angiography seemed to have better overall diagnostic accuracy than computed tomography angiography and duplex ultrasonography, and was preferred by patients over conventional angiography. It might therefore be a viable alternative to conventional contrast angiography for assessing patients with peripheral arterial disease before treatment. We could not identify enough data to assess the effectiveness of the imaging tests in terms of surgical planning and postoperative outcomes. In addition, the lack of data on severity of disease and comorbidities reported by the included studies reduces the generalisability of these findings.

Contributors: See bmj.com

Funding: Health Technology Assessment Programme (project No 03/07/04).
Competing interests: $\mathrm{EB}$ is now director of a company that undertakes consulting associated with medical imaging research. Neither she nor JK received payment for their contributions to this review. Ethical approval: Not required.

1 Collins R, Cranny G, Burch J, Aguiar-Ibáñez R, Craig D, Wright K, et al. A systematic review of duplex ultrasound, magnetic resonance angiography and computed tomography angiography for the diagnosis and assessment of symptomatic, lower limb peripheral arterial disease. Health Technol Assess 2007;11:1-202.

2 Whiting P, Rutjes A, Reitsma J, Bossuyt P, Kleijnen J. The development of QUADAS: a tool for the quality assessment of studies of diagnostic accuracy included in systematic reviews. BMC Med Res Methodol 2003;3. www.biomedcentral.com/1471-2288/3/25.

3 Unger EC, Schilling JD, Awad AN, McIntyre KE, Yoshino MT, Pond GD, et al. MR angiography of the foot and ankle. J Magn Reson Imaging 1995;5:1-5.

4 Brealey S, Westwood ME. Are you reading what we are reading? The effect of who interprets medical images on estimates of diagnostic test accuracy in systematic reviews. Br J Radiol 2007 (in press).

Accepted: 10 April 2007
Division of General Interna Medicine, University of California San Francisco, San Francisco General Hospital, 1001 Potrero Avenue, San Francisco, CA 94110, USA

${ }^{2}$ Department of Pediatrics, Children's Hospital of Philadelphia, 3400 Civic Center Boulevard, Abramson 1335 Philadelphia, PA 19104, USA

${ }^{3}$ Australian GP Statistics and Classification Centre, University of Sydney, Westmead Hospital, 2145 NSW, Australia

${ }^{4}$ University of Otago, Department of Public Health, Wellington School of Medicine and Health Sciences, PO Box 7343, Wellington, New Zealand

${ }^{5}$ Department of Primary Care and Social Medicine, Imperial College London, London

Correspondence to: A B Bindman abindman@medsfgh.ucsf.edu

BMJ 2007;334:1261-4 doi:10.1136/bmj.39203.658970.55

This article is an abridged version of a paper that was posted on bmj.com on 15 May 2007. Cite this version as: $B M J 15$ May 2007, doi: $10.1136 / \mathrm{bmj} .39203$. 658970.55 (abridged text, in print: BMJ 2007;334:1261-4)

\title{
Diagnostic scope of and exposure to primary care physicians in Australia, New Zealand, and the United States: cross sectional analysis of results from three national surveys
}

\author{
Andrew B Bindman, ${ }^{1}$ Christopher B Forrest, ${ }^{2}$ Helena Britt, ${ }^{3}$ Peter Crampton, ${ }^{4}$ Azeem Majeed ${ }^{5}$
}

\section{ABSTRACT}

Objective To compare mix of patients, scope of practice, and duration of visit in primary care physicians in

Australia, New Zealand, and the United States.

Design Comparison of three comparable cross sectional surveys performed in 2001-2. Physicians completed a questionnaire on patients' demographics, diagnoses, and duration of visit.

Setting Primary care practice.

Participants 79790 office visits in Australia, 10064 in New Zealand, and 25838 in the US.

Main outcome measures Diagnostic codes were mapped to the Johns Hopkins expanded diagnostic clusters. Scope of practice was defined as the number of expanded diagnostic clusters accounting for $75 \%$ of all managed problems related to morbidity. Exposure to primary care was calculated from duration of visits recorded by the physician, and reports on rates of visits to primary care for each country.

Results In each country, primary care physicians managed an average of 1.4 morbidity related problems per visit. In the US, 46 expanded diagnostic clusters accounted for $75 \%$ of problems managed compared with 52 in Australia, and 57 in New Zealand. Correlations in the frequencies of managed health problems between countries were high (0.87-0.97 for pairwise comparisons). Though primary care visits were longer in the US than in New Zealand and Australia, the per capita annual exposure to primary care physicians in the US (29.7 minutes) was about half of that in New Zealand ( 55.5 minutes) and about a third of that in Australia ( 83.4 minutes) because of higher rates of visits to primary care in these countries.
Conclusions Despite differences in the supply and financing of primary care across countries, many aspects of the clinical practice of primary care physicians are remarkably similar in Australia, New Zealand, and the US.

\section{INTRODUCTION}

Previous studies show that the strength of a country's primary care infrastructure is positively associated with health outcomes and negatively associated with healthcare costs. ${ }^{1}$ Limited research has been done on the clinical content and duration of visits in primary care across countries. We sought to characterise the diagnostic scope of and exposure to primary care in three countries-Australia, New Zealand, and the United States - that vary in the supply of primary care physicians, the accessibility to primary care through health insurance, and the role of primary care physicians as gatekeepers to specialty care.

Of the three countries, Australia has the greatest number of primary care physicians per 100000 population and the largest proportion of physicians trained in primary care specialties (table). In Australia and New Zealand, primary care physicians are trained as general practitioners. In the US, general internists, general paediatricians, and family practitioners all contribute to the pool of primary care physicians.

During the study period about 41 million Americans, (15\% of the total population) were uninsured and another 16 million adults aged 19-64 were underinsured. The national insurance benefits in New Zealand and Australia include cost sharing except for some low 
Characteristics of primary care by country, 2001-2

\begin{tabular}{|c|c|c|c|}
\hline & Australia & $\begin{array}{c}\text { New } \\
\text { Zealand }\end{array}$ & $\begin{array}{l}\text { United } \\
\text { States }\end{array}$ \\
\hline $\begin{array}{l}\text { Primary care physicians/ } \\
100000 \text { population }\end{array}$ & 112 & 78 & 87 \\
\hline $\begin{array}{l}\text { Percentage of primary care } \\
\text { physicians }\end{array}$ & 56 & 42 & 36 \\
\hline $\begin{array}{l}\text { Percentage of population } \\
\text { uninsured for primary care }\end{array}$ & 0 & 0 & 15 \\
\hline $\begin{array}{l}\text { Percentage with primary care } \\
\text { gatekeeping for specialty care }\end{array}$ & 100 & 100 & 38 \\
\hline $\begin{array}{l}\text { Mean No of primary care } \\
\text { visits/person/year }\end{array}$ & 5.2 & 3.7 & 1.8 \\
\hline
\end{tabular}

income patients. A portion of the population has private insurance to supplement public coverage, but private insurance does not typically cover primary care services.

In Australia and New Zealand, primary care physicians serve as gatekeepers who coordinate and manage access to specialists through their referrals. Some health plans in the US require patients to use primary care physicians to access specialty care, but many patients access specialty care services directly. ${ }^{2}$

We hypothesised that there would be substantial overlap in the practice of primary care across the three countries, but key differences in the US healthcare system would contribute to some observed differences in diagnostic scope of practice and exposure time to primary care physicians across countries.

\section{METHODS}

We used three independent nationally representative cross sectional surveys to compare mix of patients, scope of practice, and duration of visit among primary care physicians in Australia, New Zealand, and the US. We used the bettering the evaluation and care of health $(\mathrm{BEACH})$ survey in Australia ${ }^{3}$; the national primary medical care survey (NatMedCa) in New Zealand ${ }^{4}$; and the national ambulatory medical care survey (NAMCS) in the US. ${ }^{5}$ The questionnaires include

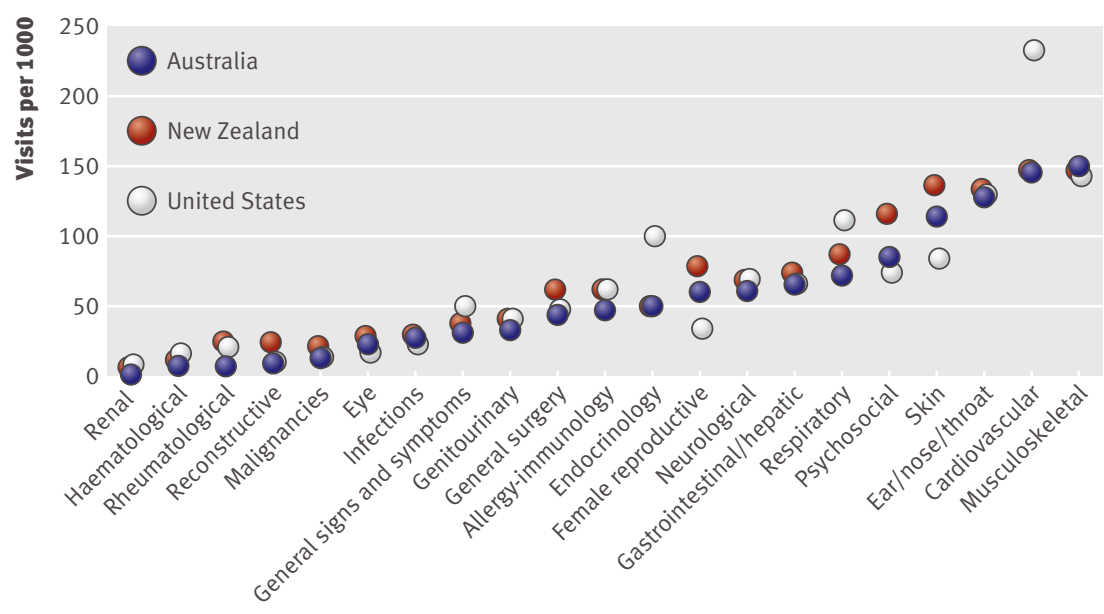

Fig 1 Age standardised frequency of health problems managed in primary care in Australia, New Zealand, and the US: 2001-2 items on whether the encounter is for a new or follow-up patient, patients' demographics and diagnoses, and duration of visit. The reporting periods are spread evenly throughout the year to reflect seasonal differences. See bmj.com for survey details.

Analysis was limited to office based face to face encounters in which the physician recorded one or more diagnosis codes for morbidities treated during the visit. We excluded visits in which physicians recorded only administrative, process, or preventive care codes - the latter because preventive care is not well described by diagnostic codes. Physicians recorded diagnoses in free text and trained coders converted these into the classification system used in that country. To create a common taxonomy for this study, we re-assigned all diagnostic codes to an expanded diagnostic cluster. These clusters are clinically homogeneous groups of diagnostic codes (see bmj.com). ${ }^{6}$

We defined a problem managed as a unique expanded diagnostic cluster within a visit. To characterise the scope of primary care practice in each country, we calculated the minimum number of expanded diagnostic clusters that accounted for $75 \%$ of the problems managed in primary care. This provided us with a means to summarise the comprehensiveness of primary care practice in each country. We interpreted the analysis of the $75 \%$ of problems managed according to the principle that the higher the number of problems the greater the comprehensiveness of practice.

We recorded duration of visit in minutes of face to face time between a patient and physician. We calculated the annual per person exposure to primary care for each country by multiplying the average duration times of primary care visits by the average number of primary care visits per person for the same time period derived from separate sources.

We age standardised results for the US and New Zealand to the Australian population. Because our parameter of the number of problems managed that comprise $75 \%$ of problems seen in primary care was a quartile $(75$ th centile of the distribution of diagnosis), we used a bootstrap method to estimate the confidence interval.

\section{RESULTS}

The surveys included 79790 office based visits to primary care in Australia, 10064 in New Zealand, and 25838 in the US. The excluded visits, in which only an administrative or preventive care code was recorded, ranged from $7 \%$ in New Zealand to $13 \%$ in Australia and $21 \%$ in the US. The remaining visits involved the management of at least one medical problem. Patients aged 65 years or older accounted for similar proportions of total visits in each country, but a greater proportion of visits in the US involved children $(30 \%)$ than in Australia (17\%) or New Zealand $(27 \%)$. Females accounted for more than half of the visits to primary care, and new patients comprised less than $10 \%$ of the visits in each country.

In each country, primary care physicians dealt with an average of 1.4 problems per visit. Those in the US, 


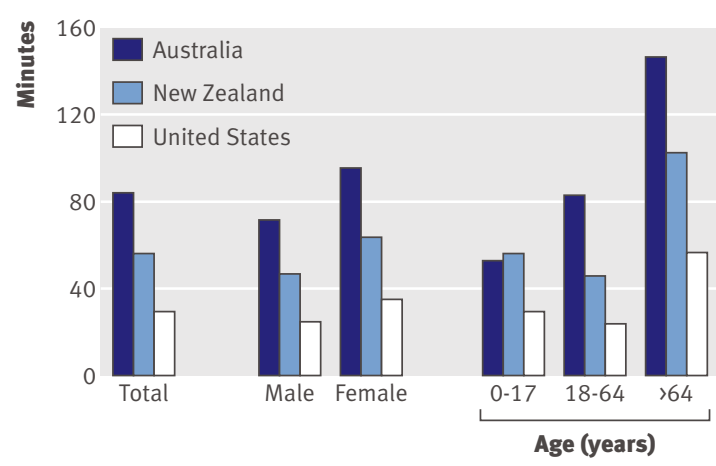

Fig 2 | Mean per capita annual exposure to primary care physicians by country and demographic subgroups: $2001-2$

however, managed a narrower range of problems. In the US, 46 (95\% confidence interval 45 to 47$)$ conditions accounted for $75 \%$ of problems managed in primary care compared with 52 (52 to 53) in Australia and 57 (56 to 59$)$ in New Zealand.

The relative frequency of health problems managed in primary care was similar across the study countries (fig 1). Correlations in the frequencies of managed health problems between countries were 0.87 for the pairwise comparison between US and New Zealand, 0.90 between Australia and the US, and 0.97 between US and Australia. Strikingly, nearly 18 per 1000 visits in the US were for obesity; almost twice the rate for this condition in Australia (11.3) and New Zealand (9.1).

The average duration of a visit was about $10 \%$ longer in the US than in Australia and New Zealand for all age and sex groups. They were 16.5 minutes (16.4 to 16.6) in the US compared with 15.0 minutes (14.3 to 15.6$)$ in New Zealand and 14.9 minutes (14.6 to 15.2) in Australia. Because the average number of primary care visits per capita was greater in New Zealand and Australia, however, the per capita annual exposure to primary care physicians was substantially lower in the US. The mean time spent per year in primary care was 29 . 7 minutes (29.5 to 29.9 ) in the US, 55.5 minutes $(52.8$ to 57.8 ) in New Zealand, and 83.4 minutes (81.9 to 84.8) in Australia (fig 2).

\section{DISCUSSION}

Despite differences in supply and financing, many aspects of the clinical practice of primary care physicians are remarkably similar in Australia, New

\section{WHAT IS ALREADY KNOWN ON THIS TOPIC}

The strength of a country's primary care infrastructure is positively associated with health outcomes and negatively associated with healthcare costs

\section{WHAT THIS STUDY ADDS}

The number and type of problems managed per primary care visit in Australia, New Zealand, and the United States are similar

Primary care is less comprehensive in the US than in Australia or New Zealand and the average American receives about half the exposure to primary care physicians compared with people in New Zealand and about a third that of people in Australia
Zealand, and the US. There is a high level of agreement in primary care across countries in the number of problems that are managed per visit, the types of problems that are managed, and the duration of visits.

\section{Diagnostic scope of practice}

The similarity in the types of problems managed within primary care across countries implies that primary care practice is a definable area of clinical work and not merely activities not performed by specialists. The finding that the range is narrower in the US than in Australia and New Zealand, however, also suggests that the comprehensiveness of primary care is influenced at the margin by the amount of specialisation in the healthcare system.

The high proportion of specialist physicians in the US in combination with the ability of patients to self refer for specialty services results in some patients seeing only specialists for ambulatory care services. ${ }^{7}$ Our results suggest that the availability of specialist physicians might also contribute to defining the range of problems managed in primary care, such as lower rates of visits for reproductive problems in women since most women have direct access to gynaecologists. The presence of general internists and general paediatricians among US primary care physicians may contribute to a narrower diagnostic scope of practice in the US. Differences in rates of visits for specific problems might also reflect national differences in the prevalence of conditions or health seeking behaviour. Our data do not allow us to determine this.

\section{Exposure to primary care}

The biggest difference in practice across the three countries is the substantially shorter time per capita in the US. The severe shortfall of available time in primary care for prevention and chronic care management could partially explain why the US does not have health outcomes that correspond to its overall investment in health care. ${ }^{8}$

Exclusion of visits in which only administrative, process, or preventive care codes were recorded limits our ability to count the amount of preventive care that is actually occurring in primary care. However, we have an accurate estimate of the exposure to primary care by country. This estimate includes all visits, even those in which only preventive, administrative, or process codes would have been recorded.

\section{Limitations}

Limits to our results are, firstly, that we looked at only three countries so limiting generalisability. Secondly, there were differences in how some questions were asked and coded in the different surveys. Although we limited the introduction of bias, our results may still include measurement artefact. Thirdly, the available cross sectional observational data limit our ability to draw causal inferences about differences in quality of care. 


\section{Summary}

One of the current objectives of the UK government is to shift services from hospital based to primary care settings. ${ }^{9}$ This raises questions about the appropriate balance between services supplied by primary care physicians and specialists. Comparisons between countries offer an opportunity to learn from natural experiments and may provide insights into how primary care can best contribute to equitable, efficient, and effective healthcare systems.

We thank Robin Osborn and her staff at the Commonwealth Fund who encouraged and believed in the value of this international collaboration, Arpita Chattopadhyay for her assistance in developing the program for running the bootstrap analysis, and Glenna Auerback for her editorial assistance. We thank Lisa Valenti for assisting with the analysis of the BEACH data, and Peter Davis, Antony Raymont, Roy Lay-Yee, and the NatMedCa research team for access to their data.

\section{Contributors: See bmi.com.}

Funding: Commonwealth Fund. BEACH 2001-2 was funded by the Australian Government Department of Health and Ageing, AstraZeneca (Australia), Aventis Pharma, Roche Products, Janssen-Cilag, and Merck Sharp and Dohme (Australia). The NatMedCa survey was funded by the Health Research Council of New Zealand. The National Ambulatory Medical Care Survey is administered and maintained by the National Center for Health Statistics of the US Department of Health and Human Services.
Competing interests: None declared.

Ethical approval: Not required.

1 Starfield B, Shi L. Policy relevant determinants of health: an international perspective. Health Policy 2002;60:201-18.

2 Ferris TG, Chang Y, Blumenthal D, Pearson SD. Leaving gatekeeping behind-effects of opening access to specialists for adults in a health maintenance organization. N Engl J Med 2001;345:1312-7.

3 Britt H, Miller GC, Knox S, Charles J, Valenti L, Henderson J, et al. General practice activity in Australia 2001-02. Canberra: Australian Institute of Health and Welfare, 2002. www.aihw.gov.au/ publications/gep/gpaa01-02/gpaa01-02.pdf.

4 Ministry of Health. 2004. Family doctors: methodology and description of the activity of private GPs: the national primary medical care survey (NatMedCa): 2001/02. Report 1. Wellington: Ministry of Health. www.moh.govt.nz/moh.nsf/wpg Index/Publications-Family + Doctors+NatMedCa+Report+One.

5 National Ambulatory Medical Care Survey (NAMCS). Atlanta (GA): Centers for Disease Control and Prevention, 2007. www.cdc.gov/ nchs/about/major/ahcd/namcsdes.htm.

6 The Johns Hopkins University ACG case-mix system. 2007. www.acg. jhsph.edu/ResourceCenter.aspx?Type=Documentation.

7 Rosenblatt RA, Hart LG, Baldwin LM, Chan L, Schneeweiss R. The generalist role of specialty physicians: is there a hidden system of primary care? JAMA 1998;279:1364-70.

8 Reinhardt UE, Hussey PS, Anderson GF. Cross-national comparisons of health systems using OECD data, 1999. Health Aff 2002;21:169-81.

9 Department of Health. Our health, our care, our say: a new direction for community services. London: Department of Health, 2006. www. dh.gov.uk/assetRoot/04/12/74/59/04127459.pdf.

Accepted: 9 April 2007

\section{An event that changed our lives}

A telephone call during a duty evening in a doctor's sitting room in Stockton-on-Tees in January 1970 was usually a request for a home visit. But this call was from a general practitioner in Ontario inquiring about a six month exchange of practices. Eleven weeks later, we had swapped jobs and, with the support of home based wives, had exchanged cars, children's school places, and prebooked holidays. Trusted accountants equated the finances. This event gave us a vision of our futures, the ways we wished our practices to progress, and led to lifelong friendship.

Practising in "renovated" old buildings in Stockton and a converted house in Canada showed that expansion of premises was vital for teamwork, teaching, and research: both practices now have modern, purpose-built premises. The British doctor realised that the Canadian system of having an individual list of patients, albeit within a group of four doctors, was fundamental to continuing personal care: on his return, the British practice was divided into five. The Canadian GP appreciated that capitation payment encouraged and facilitated team care: his practice became one of the first to be "capitation funded" in Ontario. From the team, the British doctor sorely missed the midwife (particularly at deliveries); the Canadian doctor soon appreciated her role. She has now usurped GP maternity care - in urban Canada it has become increasingly specialist orientated.

Visits to the McMaster University nurse practitioner programme showed nurses' potential in the team: nurses' roles have expanded in UK practices, but, paradoxically, this is still uncommon in Ontario.

Repetitive doctor "checks" of babies indicated a need to share care with health visitors - not part of the practice team in Canada but common in the UK. The British doctor was appalled by the frequency and futility of "well physicals": the Canadian doctor was delighted not to do any, although feeling that some would be of value. Nurse-run "well person clinics" are now essential in British general practice. Despite all the health checks, the obesity epidemic was well advanced in Canada in 1970 and is now widespread in both countries. The Canadian tolerated the futility of many house calls, and the British doctor realised that, with increasing ownership of telephones and cars, they would almost cease The British doctor visited his hospitalised patients but was unconvinced of the value. There seemed little future for this in Britain - in Canada it has reduced. The Canadian doctor despaired of trivial British consultations merely to certify inability to work-now reduced.

The British doctor rapidly realised that he had been "on a pedestal" in the UK: he was summarily knocked off it by his Canadian patients. He realised that a shared, problemcentred approach would be the future and that patients would increasingly question, debate, and occasionally litigate.

Using each other's place of work, and homes, has been followed by sharing lives. We have watched each other's careers and now those of our children. The British doctor treasures memories of friendly Canadians, of Niagara Falls by day and night, of unspoilt nature around the Great Lakes, and of burgeoning cities. The Canadian remembers afternoon tea and cream cakes, "the boys" playing cricket, northern moors and dales, the south Devon coast, the Highlands, the Ring of Kerry.

Now retired, we have trekked together in Britain and portaged in northern Ontario; lunched in Pisa's Campo dei Miracoli, marvelled as the sun set on the mosaics of Orvieto's Duomo, heard aghast of the 11 September atrocity in the shadow of Giotto's campanile in Florence, drunk Chateauneuf du Pape in that very town, gazed at Gaudi's work in Barcelona ... we are enjoying old age. One day there will be memorial benches in Swaledale and beside Lake Neighick in northern Ontario.

Geoffrey Marsh retired general practitioner, Stockton-on-Tees geoffreynmarsh@yahoo.co.uk Patrick Sweeny retired general practitioner, Burlington Ontario, Canada 